\title{
Complexity in animal behaviour: towards common ground
}

\section{Hélène Cochet \& Richard W. Byrne}

acta ethologica

ISSN 0873-9749

acta ethol

DOI 10.1007/s10211-014-0205-5

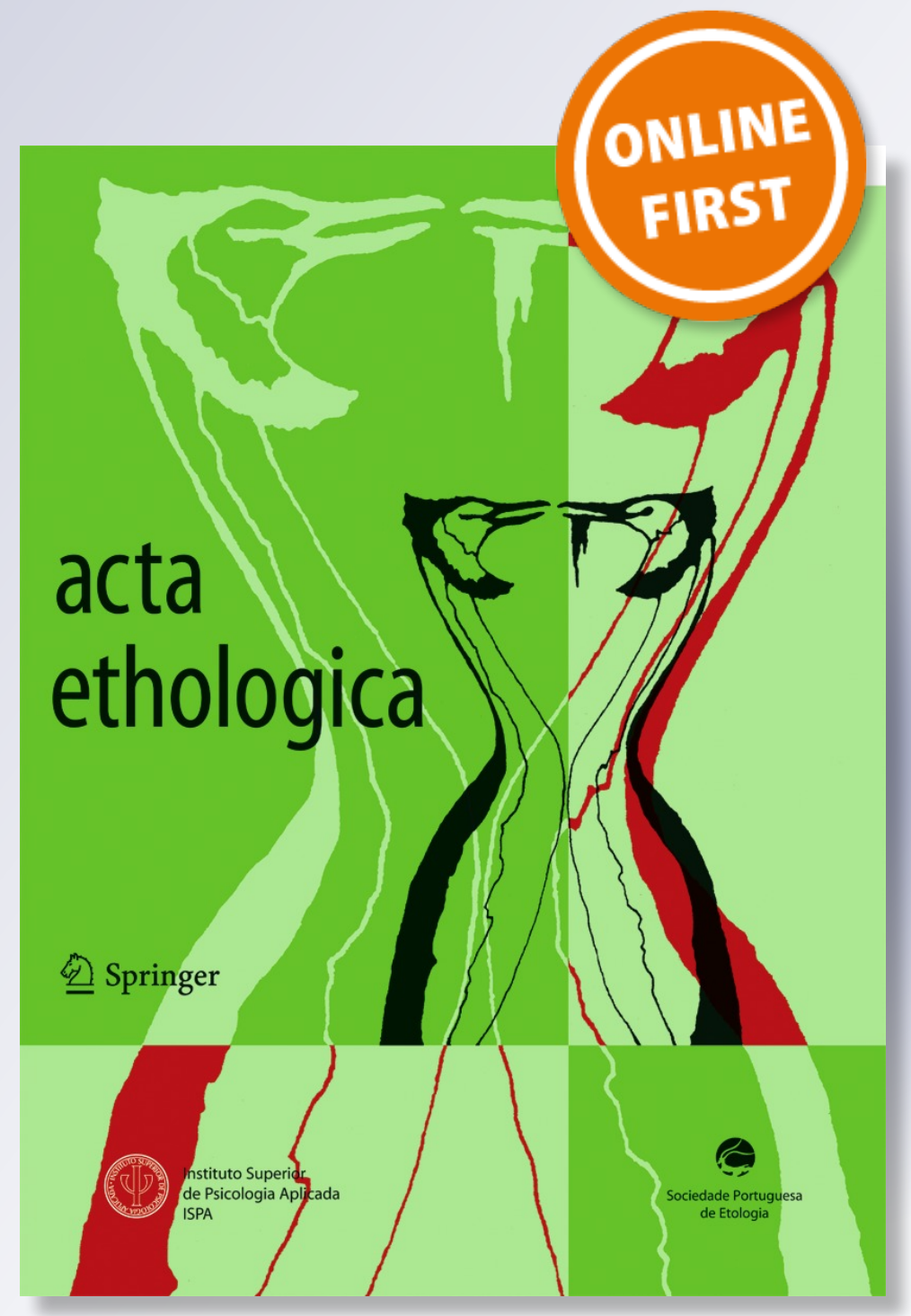

望 Springer 
Your article is protected by copyright and all rights are held exclusively by Springer-Verlag Berlin Heidelberg and ISPA. This e-offprint is for personal use only and shall not be selfarchived in electronic repositories. If you wish to self-archive your article, please use the accepted manuscript version for posting on your own website. You may further deposit the accepted manuscript version in any repository, provided it is only made publicly available $\mathbf{1 2}$ months after official publication or later and provided acknowledgement is given to the original source of publication and a link is inserted to the published article on Springer's website. The link must be accompanied by the following text: "The final publication is available at link.springer.com". 


\title{
Complexity in animal behaviour: towards common ground
}

\author{
Hélène Cochet • Richard W. Byrne
}

Received: 30 May 2014 / Revised: 3 September 2014 / Accepted: 29 September 2014

(C) Springer-Verlag Berlin Heidelberg and ISPA 2014

\begin{abstract}
The ambiguity of the term 'complex' in studies of animal behaviour and cognition can lead to theoretical and methodological disputes, as there seems to be little common ground regarding the features thought to introduce complexity. Based on examples not only in human and nonhuman primates but also in some species of birds, we explore three dimensions of complexity: motor precision, coordination, and anticipatory planning. We argue that it is necessary to identify which dimensions are present in each study to formulate and explore relevant questions in behavioural sciences, especially with an evolutionary perspective.
\end{abstract}

Keywords Complexity · Animal behaviour · Cognition · Evolution

The use of the adjective complex is increasingly common in the literature on animal behaviour and seems to cover a wide range of meanings in different species. Consider, for example, whether the 'complexity' cited by the original researchers was in any way the same thing in these three cases: vocal learning in some species of birds (e.g. Jarvis et al. 2000), following pointing signals (e.g. in crows, Taylor et al. 2010; in dogs, Elgier et al. 2012), and symbolic conceptual reasoning (e.g. Seed and Tomasello 2010). These few examples show that there is little common ground to understand the term

\footnotetext{
H. Cochet $(\triangle)$

Octogone-ECCD, University of Toulouse-Jean Jaurès, 5 allées

Antonio Machado, 31058 Toulouse Cedex 9, France

e-mail: helene.cochet@univ-tlse2.fr

R. W. Byrne

Centre for Social Learning and Cognitive Evolution, Scottish Primate Research Group, University of St Andrews, School of Psychology and Neuroscience, St Mary Squad, South Street, St Andrews, Fife KY16 9JP, UK

e-mail: rwb@st-andrews.ac.uk
}

complexity in the field of animal behaviour and cognition. Most of the time, ill-defined claims of complexity are made, more or less consciously, to champion the cognitive abilities of one's particular species. This becomes particularly problematic when researchers wish to use the comparative method to deduce evolutionary history and need to compare disparate sorts of animals: for instance, making comparisons between corvids, apes, and cetaceans (e.g. Emery and Clayton 2004; Marino 2002; Marino et al. 2007; Van Horik et al. 2012). There have been previous attempts to measure complexity on a single scale, for instance, by counting components (Sambrook and Whiten 1997) but here we argue that it may be necessary to describe complexity along several different dimensions. Identifying explicitly which dimensions are examined in each study should allow researchers to go beyond the often fruitless opposition of simple vs. complex mechanisms, which seems to have replaced the opposition of lower vs. higher cognition current in the mid-19th to the mid/late20th century.

Too often, complex cognition is treated as an 'explanation' of behaviour that can apparently not be explained by associative processes; this categorization, generally implicit, tends to result in a heterogeneous category in which the complexity is of many different sorts. Moreover, it is difficult to disentangle the cognitive nature of these mechanisms since they are not directly palpable, especially in species that do not use language. Incomplete knowledge of animal behaviour and cognition may lead scientists to accept hypotheses because they are simpler to comprehend than alternative accounts (e.g. Heyes 1998), and sometimes, the possibility cannot be excluded that tasks characterized as complex are solved by taking advantage of a given species' gene pool or by learning task-specific responses in a situation rather than by applying general cognitive principles (see Byrne et al. 2013).

Focusing mainly on data in primates and birds, we describe here three key dimensions of complexity (which are not 
necessarily exhaustive), namely complexity in motor precision, complexity in coordinating activities or information, and complexity in planning. We review several studies in the recent literature, illustrating both individual and social activities and show that behaviour sometimes involves several dimensions of complexity.

\section{Complexity in motor precision}

The difficulty of any motor behaviour is tightly linked to the degree of accuracy required for a specific activity and the speed with which it can be done (Fitts 1954) but there is no clear consensus on the characteristics that define motor skills as complex. For example, complexity has been claimed to lie in 'exceptionally precise and rapid control of musculature' (birdsong, Tumer and Brainard 2007), in fine control of hand and finger movements in humans (and more specifically in using fingers in 'a nonconsecutive and non-repetitive order', Gerloff et al. 1998), and motor skills have also been characterized as complex, without any explicit definition, in invertebrates (Sanes and Donoghue 2000).

However, what makes a task difficult is likely to vary with the species under study and the activity considered. Motor skills are generally measured through the capacity to perform a specific task, in terms of efficiency (e.g. success rate across trials) or speed of movements. Complex motor actions mainly involve fine motor abilities, in particular, manual dexterity. Dexterity is usually assessed in a laboratory, for example, in peg-moving tasks (Annett 1970) or dot-tapping tasks (Tapley and Bryden 1985). The motor skills required to move dowel pegs quickly from one row of holes to another row are also primarily governed by genetic factors (the rate of learning being also significantly heritable, e.g. Fox et al. 1996), which emphasizes the relatively automatic level of variation at which behaviour is sometimes referred to as complex. This adjective thus does not seem very enlightening when it describes motor behaviour and should be used, if ever, with some caution.

Complexity in motor precision can also be highlighted at a social level, i.e. when more than one individual is involved. Adjusting to another person's body or hands may necessitate fine motor precision (see Table 1), although little research has been conducted on this question.

In addition to the ability vs. inability to perform motor tasks and the speed of performing them, considering a specific example reveals another dimension of complexity: the degree of precision needed to hold and manipulate small objects requires the ability to coordinate the thumb and the index finger to form a precision grip (Napier 1956), an ability that develops in human infants at the end of the first year. A key aspect of complexity may thus be based on the notion of coordination, which we consider next.

\section{Complexity in coordination}

Manual skills may involve being able to integrate and coordinate several elements together; for many complex actions, coordination may represent a key feature of skill. For instance, activities requiring the coordination of the two hands, especially when the latter plays highly differentiated roles (e.g. striking a match with one hand while holding the box with the other hand), have been characterized as complex in human and nonhuman primates (e.g. natural foraging, Byrne and Byrne 1993; the tube task, Fagard and Marks 2000; Hopkins et al. 2005).

Complexity in coordinated actions has been indicated in tool manufacture and tool use, in great apes (e.g. in chimpanzees, 'design complexity in termite-fishing tools', Sanz et al. 2009) and also in several species of birds (e.g. in cockatoos, 'complex tool innovations', Auersperg et al. 2012; in crows, 'complex behaviour such as tool manufacture' Kenward et al. 2005). Here, complexity has been defined as 'the degree of transformation necessary to produce a functional tool from the raw material' (Kacelnik et al. 2006, p. 7); different degrees of complexity can thus be distinguished, starting from the use of unmodified objects. Multistep tool-making most likely involves the highest level of coordination: adding, combining, or restructuring material to act on a specific target may even require some causal understanding of the relationships between different objects (e.g. Vaesen 2012). Moreover, the emergence of coordination skills in tool use and tool manufacture has long been hypothesized to play a key role in human evolution, in particular during the Paleolithic lithic revolution (e.g. Steele 1999).

In addition, chimpanzees have been reported to use several different tools successively: each tool specialized for a specific purpose. The use of such 'complex tool sets' (Boesch et al. 2009) may reflect sequential coordination: where the necessary starting conditions for applying one tool must first be realized by applying another different tool. Coordination here extends over time rather than space. Sequential coordination is also involved in other activities, such as choosing one's route to go from one place to another, when several route segments - each learned separately through experience-are coordinated into a novel route.

Social interactions may also require coordination. In numerous animal species, individuals adjust their own behaviour to others' actions. Interindividual coordination may reach a higher degree of complexity when intentional and referential signals are directly addressed to specific individuals who can interpret these signals and respond by moderating their behaviour accordingly. Joint attention skills are a typical example of such coordination, whether they involve bodyorienting, eye-gazing, pointing, or verbal indications. Joint attention has mainly been reported in the human species (e.g. in young children, Liszkowski et al. 2004), but not 
Table 1 Illustration of the three dimensions of complexity expressed from individual and social perspectives

\begin{tabular}{|c|c|c|}
\hline & Individual & Social \\
\hline 1. Motor precision & $\begin{array}{l}\text { Accuracy and speed in positioning hand(s) with fixed } \\
\text { environment (e.g. Peg-moving task in humans: } \\
\text { Holper et al. 2009) }\end{array}$ & $\begin{array}{l}\text { Accuracy and speed in positioning hand(s) with other } \\
\text { person's body or hands (e.g. playing skipping rope: } \\
\text { one person turns the rope, which is anchored at the } \\
\text { other end, while another jumps) }\end{array}$ \\
\hline 2. Coordination & $\begin{array}{l}\text { Coordination of the two hands (e.g. gorilla nettle-leaf } \\
\text { folding, Byrne and Byrne 1993; the tube task in } \\
\text { primates, Vauclair et al. 2005) } \\
\text { Coordination of two fingers (e.g. transferring item to } \\
\text { lower fingers to enable precision grip to be used } \\
\text { between index finger and thumb while still holding } \\
\text { items, Connolly and Dalgleish } 1989 \text { in human } \\
\text { infants; Byrne et al. } 2001 \text { in gorillas) } \\
\text { Coordination over time (sequential coordination): } \\
\text { performing a sequence of action to reach a specific } \\
\text { goal (e.g. cooking in humans, honey extraction from } \\
\text { bee nests in chimpanzees, Boesch et al. 2009) }\end{array}$ & $\begin{array}{l}\text { Adjusting to others' behaviour (e.g. playing tennis, } \\
\text { playing skipping rope: two people turn the rope } \\
\text { while one or more persons jump; collaborative } \\
\text { interactions in social games in gorillas, Tanner } \\
\text { and Byrne 2010) }\end{array}$ \\
\hline 3. Anticipatory planning & $\begin{array}{l}\text { Mentally reviewing an intended action sequence to } \\
\text { anticipate a future need (e.g. shopping without a } \\
\text { list in humans to cook a specific dish, making } \\
\text { termite-fishing tools in advance of need, } \\
\text { Goodall 1986; Byrne et al. 2013) }\end{array}$ & $\begin{array}{l}\text { Intention-reading abilities, rational imitation, } \\
\text { pedagogical teaching (in human infants, } \\
\text { Bellagamba et al. 2006; Gergely et al. 2002) }\end{array}$ \\
\hline
\end{tabular}

exclusively (e.g. in magpies, Kaplan 2011; in gorillas, Tanner and Byrne 2010).

However, as we mentioned in the introduction, we still need to determine to what extent the complexity of coordination, both at the individual and social levels, lies in cognitive processes yet to be deciphered. For example, nest building has been argued to require complex cognition (in birds, Healy et al. 2008) and engineering skills (in orang-utans, Van Casteren et al. 2012) but complexity of manufacture does not always imply complexity of cognition, and it is actually challenging to demonstrate the cognitive aspects of these behaviours. Similarly, the ability to integrate and adjust to others' actions does not necessarily require any understanding of others' knowledge or intentions. In those cases where tooluse activities $d o$ require anticipation of causal consequences or social coordination requires taking account of other's mental states, we must consider another dimension of complexity altogether, which we consider below.

\section{Complexity in planning}

With many activities, even those involving tool-use or toolmaking, it is a moot point whether they can be fully explained as being driven by individuals' current perceptual assessment of a particular context or require postulation of the ability to represent the relationship between a sequence of actions and a specific goal (e.g. Wimpenny et al. 2009). But in some cases, it is clear that representation is involved when there is evidence of some assessment of the whole problem in advance of action, such as making or selecting an appropriate tool well before the place and time of use. This requires another dimension of complexity: anticipatory planning capacity. Futureoriented behaviours have long been considered to be uniquely human (and they have been widely studied in our species, e.g. Friedman et al. 1987) but nonhuman primates (e.g. Byrne 1998; Byrne et al. 2013; Mulcahy and Call 2006; Osvath 2009) and several species of birds have been reported to anticipate future need states by shaping and selecting tools (in rooks, Bird and Emery 2009; in New Caledonian crows, Kacelnik et al. 2006) or making food provision (in jays, Raby et al. 2007) depending on their future needs and purposes. The manufacture of different tools in goal-directed activities may reveal knowledge about these situations and planning abilities and have been argued to demonstrate 'high intelligence' (in wild chimpanzees, Sugiyama 1997). The fact that tool selection is influenced by environmental factors such as nut resistance (e.g. Luncz et al. 2012; and see Walsh et al. 2010 for a similar argument for bird nest building) has also been used as an argument supporting the complexity of this behaviour.

When we consider interindividual interactions, anticipatory planning skills imply the ability to predict another person's behaviour, potentially underwritten by the ability to discern and represent that person's knowledge and intentions. Mentalizing skills have been argued to characterize the human species, developing from the second and third years of life (e.g. Bellagamba et al. 2006; Kawakami et al. 2011). Although nonhuman primates are able to cooperate in experimental situations involving food competition, they do not seem to use cues that would reveal mutual understanding of 
each other's intentions (e.g. Bullinger et al. 2011). Other researchers have reported planning abilities in a tool-use task but not in an exchange task in chimpanzees (Dufour and Sterck 2008), suggesting that the capacity to mentally represent a situation sufficiently to allow anticipatory planning may be limited to nonsocial contexts.

However, the interpretations associated with the question of goal-directed behaviours and mental representations vary widely depending on the authors: results may be explained in reference to socio-cognitive skills, even 'rudimentary mindreading' (in corvids, Seed et al. 2009), while less cognitively complex strategies may be invoked by other researchers (Vasconcelos et al. 2012). Conventional learning, which can rely on social learning in addition to the possibility of training in captive subjects, has been repeatedly opposed to more abstract forms of reasoning like anticipatory planning, in particular for nonhuman animals (e.g. Raby and Clayton 2009; Tebbich and Bshary 2004), and these learning processes do not necessarily imply a plan computed beforehand via a mental representation of a given situation. We clearly see here the need for explicit definitions of core concepts related to cognition. The strict distinction between goal-directed behaviour and future planning, along with the investigation of several plausible accounts of the latter behaviour (see Dickinson 2011, for a description of mnemonic-associative theory and mental time travel account), may be important directions to consider.

\section{Conclusion}

The term complex is misleadingly ambiguous, used to describe sequences of actions (e.g. tool manufacture), communicative signals (e.g. Ord and Martins 2006), and specific behaviours likely to involve mental processes (e.g. joint attention). We argue that this ambiguity can be greatly reduced by teasing out three dimensions: motor precision, coordination, and planning, each of which may involve individual and/ or social activities (see Table 1). The complexity of a given mechanism/behaviour can be assessed by distinguishing which of these three dimensions are involved and to what degree. Moreover, although the distinction of several dimensions of complexity can clarify our understanding of animal behaviour and cognition, it is important to keep in mind that some activities involve more than one dimension. These independent aspects of complexity being potentially additive, social activities which involve motor precision, coordination, and anticipatory planning would thus represent greater complexity. For example, nut-cracking in chimpanzees necessitates not only manual precision in aiming and the coordination of the two hands (see Sections 1 and 2) but also the anticipation of a sequence of actions to feed from the nut, therefore, combining several dimensions of complexity. Several animal species show complex behaviour measured in this way, with perhaps the greatest cognitive challenge arising from interactions, including those between predator and prey but particularly those conspecific interactions requiring the ability to reason cooperatively with others (e.g. Byrne and Bates 2010). However, the planning abilities that characterize human cognition, reflected in particular in intentional communication and cultural learning, may represent an even more challenging form of complexity (Seed and Tomasello 2010).

Acknowledgements This work was supported by a postdoctoral research grant from the Fyssen foundation. The core idea of this article stems from discussions with the researchers attending the Tarragona Laterality Conference in February 2013.

\section{References}

Annett M (1970) The classification of hand preference by association analysis. Brit J Psychol 61:303-321

Auersperg AMI, Szabo B, von Bayern AMP, Kacelnik A (2012) Spontaneous innovation of tool use and flexible manufacture in the Goffin's cockatoo (Cacatua goffini). Curr Biol 22:903-904

Bellagamba F, Camaioni L, Colonnesi C (2006) Change in children's understanding of others' intentional actions. Dev Sci 9:182-188

Bird CD, Emery NJ (2009) Insightful problem solving and creative tool modification by captive nontool-using rooks. Proc Natl Acad Sci U S A 106:370-375

Boesch C, Head J, Robbins MM (2009) Complex tool sets for honey extraction among chimpanzees in Loango National Park, Gabon. J Hum Evol 56:560-569

Bullinger AF, Wyman E, Melis AP, Tomasello M (2011) Coordination of chimpanzees (Pan troglodytes) in a stag hunt game. Int J Primatol 32:1296-1310

Byrne RW (1998) The early evolution of creative thinking: evidence from monkeys and apes. In: Mithen S (ed) Creativity in human evolution and prehistory. Routledge, London, pp 110-124

Byrne RW, Bates LA (2010) Primate social cognition: uniquely primate, uniquely social, or just unique? Neuron 65:815-830

Byrne RW, Byrne JM (1993) The complex leaf-gathering skills of mountain gorillas (Gorilla $g$. beringei): variability and standardization. Am J Primatol 31:241-261

Byrne RW, Corp N, Byrne JM (2001) Manual dexterity in the gorilla: bimanual and digit role differentiation in a natural task. Anim Cogn 4:347-361

Byrne RW, Sanz CM, Morgan DB (2013) Chimpanzees plan their tool use. In: Sanz CM, Call J, Boesch C (eds) Tools use in animals: cognition and ecology. Cambridge University Press, Cambridge, pp 48-64

Connolly K, Dalgleish M (1989) The emergence of a tool-using skill in infancy. Dev Psychol 25:894-912

Dickinson A (2011) Goal-directed behaviour and future planning in animals. In: Menzel R, Fischer J (eds) Animal thinking: contemporary issues in comparative cognition. MIT Press, Cambridge, pp 79-91

Dufour V, Sterck EHM (2008) Chimpanzees fail to plan in an exchange task but succeed in a tool-using procedure. Behav Processes 79:19-27

Elgier AM, Jakovcevic A, Mustaca AE, Bentosela M (2012) Pointing following in dogs: are simple or complex cognitive mechanisms involved? Anim Cogn 15:11-19 
Emery NJ, Clayton NS (2004) Comparing the complex cognitive abilities of birds and primates. In: Rogers LJ, Kaplan G (eds) Comparative vertebrate cognition: are primates superior to non-primates? Plenum, New York, pp 3-55

Fagard J, Marks A (2000) Unimanual and bimanual tasks and the assessment of handedness in toddlers. Dev Sci 3:137-147

Fitts PM (1954) The information capacity of the human motor system in controlling the amplitude of movement. J Exp Psychol 47:381-391

Fox PW, Hershberger SL, Bouchard TJ (1996) Genetic and environmental contributions to the acquisition of a motor skill. Nature 384:356358

Friedman SL, Scholnick EK, Cocking RR (1987) Blueprints for thinking: the role of planning in cognitive development. Cambridge University Press, New York

Gergely G, Bekkering H, Király I (2002) Rational imitation in preverbal infants. Nature 415:755

Gerloff C, Corwell B, Chen R, Hallett M, Cohen LG (1998) The role of the human motor cortex in the control of complex and simple finger movement sequences. Brain 121:1695-1709

Goodall J (1986) The chimpanzees of Gombe: patterns of behavior. Belknap, Cambridge

Healy SD, Walsh P, Hansell M (2008) Nest building by birds. Curr Biol $18: 271-273$

Heyes CM (1998) Theory of mind in nonhuman primates. Behav Brain Sci 21:101-148

Holper L, Biallas M, Wolf M (2009) Task complexity relates to activation of cortical motor areas during uni- and bimanual performance: a functional NIRS study. Neuroimage 46:1105-1113

Hopkins WD, Russell J, Freeman H, Buehler N, Reynolds E, Schapiro SJ (2005) The distribution and development of handedness for manual gestures in captive chimpanzees (Pan troglodytes). Psychol Sci 16: 487-493

Jarvis ED, Ribeiro S, da Silva ML, Ventura D, Vielliard J, Mello CV (2000) Behaviourally driven gene expression reveals song nuclei in hummingbird brain. Nature 406:628-632

Kacelnik A, Chappell J, Weir AAS, Kenward B (2006) Cognitive adaptations for tool-related behaviour in New Caledonian crows. In: Wasserman EA, Zentall TR (eds) Comparative cognition: experimental explorations of animal intelligence. Oxford University Press, Oxford, pp 515-528

Kaplan G (2011) Pointing gesture in a bird - merely instrumental or a cognitively complex behaviour? Curr Zool 57:453-467

Kawakami K, Kawakami F, Tomonaga M, Kishimoto T, Minami T, Takai-Kawakami K (2011) Origins of a theory of mind. Infant Behav Dev 34:264-269

Kenward B, Weir AAS, Rutz C, Kacelnik A (2005) Tool manufacture by naive juvenile crows. Nature 433:121

Liszkowski U, Carpenter M, Henning A, Striano T, Tomasello M (2004) Twelve-month-olds point to share attention and interest. Dev Sci 7: 297-307

Luncz LV, Mundry R, Boesch C (2012) Evidence for cultural differences between neighboring chimpanzee communities. Curr Biol 22:1-5

Marino L (2002) Convergence of complex cognitive abilities in cetaceans and primates. Brain Behav Evol 59:21-32

Marino L, Connor RC, Fordyce RE, Herman LM, Hof PR, Lefebvre L, Lusseau D, McCowan B, Nimchinsky EA, Pack AA, Rendell L, Reidenberg JS, Reiss D, Uhen MD, Van der Gucht E, Whitehead H (2007) Cetaceans have complex brains for complex cognition. PLoS Biol 5:966-972
Mulcahy NJ, Call J (2006) Apes save tools for future use. Science 312: $1038-1040$

Napier JR (1956) The prehensile movements of the human hand. J Bone Joint Surg 38B:902-913

Ord TJ, Martins EP (2006) Tracing the origins of signal diversity in anole lizards: phylogenetic approaches to inferring the evolution of complex behaviour. Anim Behav 71:11-29

Osvath M (2009) Spontaneous planning for future stone throwing by a male chimpanzee. Curr Biol 19:R190-R191

Raby C, Clayton N (2009) Prospective cognition in animals. Behav Processes 80:314-324

Raby C, Alexis DM, Dickinson A, Clayton NS (2007) Planning for the future by western scrub-jays. Nature 445:919-921

Sambrook T, Whiten A (1997) On the nature of complexity in cognitive and behavioural science. Theor Psychol 7:191-213

Sanes JN, Donoghue JP (2000) Plasticity and primary motor cortex. Annu Rev Neurosci 23:393-415

Sanz C, Call J, Morgan D (2009) Design complexity in termite-fishing tools of chimpanzees (Pan troglodytes). Biol Lett 5:293-296

Seed A, Tomasello M (2010) Primate cognition. Topics Cogn Sci 2:407419

Seed A, Emery N, Clayton N (2009) Intelligence in corvids and apes: a case of convergent evolution? Ethol 115:401-420

Steele J (1999) Paleoanthropology - stone legacy of skilled hands. Nature 399:24-25

Sugiyama Y (1997) Social tradition and the use of tool composites by wild chimpanzees. Evol Anthropol 6:23-27

Tanner JE, Byrne RW (2010) Triadic and collaborative play by gorillas in social games with objects. Anim Cogn 13:591-607

Tapley M, Bryden MP (1985) A group test for the assessment of performance between the hands. Neuropsychologia 23:215-221

Taylor AH, Elliffe D, Hunt GR, Gray RD (2010) Complex cognition and behavioural innovation in New Caledonian crows. Proc R Soc Lond [Biol] 277:2637-2643

Tebbich S, Bshary R (2004) Cognitive abilities related to tool use in the woodpecker finch, Cactospiza pallida. Anim Behav 67: 689-697

Tumer EC, Brainard MS (2007) Performance variability enables adaptive plasticity of 'crystallized' adult birdsong. Nature 450:1240-1244

Vaesen K (2012) The cognitive bases of human tool use. Behav Brain Sci 35:203-218

Van Casteren A, Sellers WI, Thorpe SKS, Coward S, Crompton RH, Myatt JP, Ennos AR (2012) Nest-building orangutans demonstrate engineering know-how to produce safe, comfortable beds. Proc Natl Acad Sci U S A 109:6873-6877

Van Horik J, Clayton N, Emery N (2012) Convergent evolution of cognition in corvids, apes and other animals. In: Vonk J, Shackelford T (eds) Oxford handbook of comparative evolutionary psychology. Oxford University Press, New York, pp 80-101

Vasconcelos M, Hollis K, Nowahari E, Kacelnik A (2012) Pro-sociality without empathy. Biol Lett 8:910-912

Vauclair J, Meguerditchian A, Hopkins WD (2005) Hand preferences for unimanual and coordinated bimanual tasks in baboons (Papio anubis). Cogn Brain Res 25:210-216

Walsh PT, Hansell M, Borello WD, Healy SD (2010) Repeatability of nest morphology in African weaver birds. Biol Lett 6:149-151

Wimpenny JH, Weir AAS, Clayton L, Rutz C, Kacelnik A (2009) Cognitive processes associated with sequential tool use in New Caledonian crows. PLoS One 4:e6471 